Astrid Louise Betten Rygh, ph.d. Obstetric anal sphincter injuries. A population-based study of improvement of care. Utgår fra Klinisk institutt 1. Disputas 11.12. 2015.

Bedømmelseskomité: Jim Dornan, Queens University Belfast and Ulster University, Storbritannia, Stig Norderval, Universitetet i Troms $\varnothing$ - Norges arktiske universitet, og Line Bjørge, Universitetet i Bergen.

Veiledere: Hartwig Kørner, Torbjørn Moe Eggebøe og Finn Egil Skjeldestad.

\section{NTNU}

Det skapende universitet

http://www.ntnu.no/kalender\#tag=disputaserdmf

Gunn Hege Marchand, ph.d. Adding work-focus to multidisciplinary interventions in specialist care - clinical, social and occupational perspectives. Utgår fra Institutt for nevromedisin. Disputas 4.12. 2015.

Bedømmelseskomité: Mats Hagberg, Sahlgrenska Universitetssjukhuset, Göteborg, Sverige, Torill Helene Tveito, Uni Research Health, Universitetet i Bergen, og Chris Jensen, Institutt for samfunnsmedisin, Norges teknisk-naturvitenskapelige universitet. Veiledere: Gunnar Leivseth, Cecilie Røe og Bjørn Lau.

\section{Universitetet i Tromsø Norges arktiske universitet https://uit.no/tavla}

and efficacy of epidural injection therapy. Utgår fra Institutt for klinisk medisin. Disputas 27.11. 2015.

Bedømmelseskomité: Björn Rydevik, Institutionen för kliniska vetenskaper, Sahlgrenska akademin, Göteborgs universitet, Sverige, Aage Indahl, Sentralsykehuset i Vestfold, Kysthospitalet i Stavern, og Elise Klouman, Institutt for samfunnsmedisin, Universitetet i Troms $\varnothing$ - Norges arktiske universitet. Veiledere: Tore K. Solberg og Tor Ingebrigtsen.

Garth D. Tylden, ph.d. Investigation of the antiviral effects of lipid conjugated derivatives of cidofovir on BK and JC polyomavirus replication. Utgår fra Institutt for medisinsk biologi. Disputas 4.12. 2015.

Bedømmelseskomité: Tina Dalianis, Department of OncologyPathology, Karolinska Universitetssjukhuset, Stockholm, Sverige, Halvor Rollag, Avdeling for mikrobiologi, Universitetet i Oslo, og Kristin Andreassen Fenton, Institutt for medisinsk biologi, Universitetet i Troms $\varnothing$ - Norges arktiske universitet. Veiledere: Christine Hanssen Rinaldo og Tore Jarl Gutteberg.

Nadine Pullar, ph.d. Tuberculosis in HIV positive individuals - risk factors, diagnostic methods and follow-up in a low-endemic county. Utgår fra Institutt for klinisk medisin. Disputas 9.12. 2015.

Bedømmelseskomité: Pernille Ravn, Lunge og infektionsmedicinsk afdeling, Hillerød Hospital, Danmark, Sven Gudmund Hinderaker, Senter for internasjonal helse, Universitetet i Bergen, og Anne Mette Asfeldt, Institutt for samfunnsmedisin, Det helsevitenskapelige fakultet, Universitetet i Troms $\emptyset$ - Norges arktiske universitet.

Veiledere: Johan N. Bruun og Anne Ma Dyrhol-Riise.

\title{
Norske idrettsleger mottar Nordiska medicinpriset 2015
}

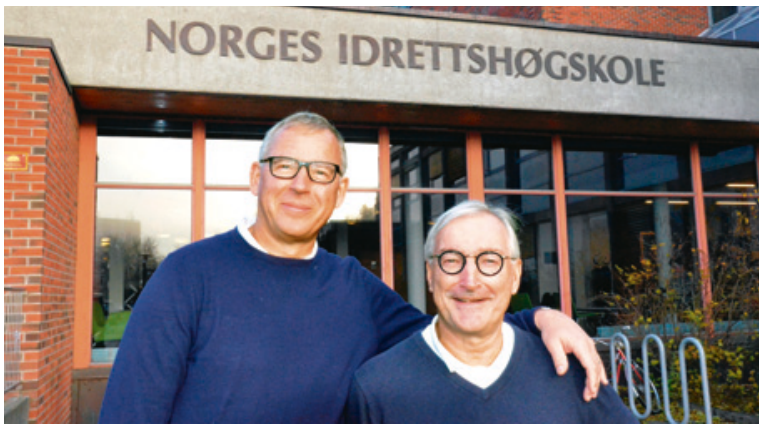

Roald Bahr og Lars Engebretsen. Foto: Karen Christensen, Norges idrettshøgskole

Lars Engebretsen (f. 1949) og Roald Bahr (f. 1957) er tildelt Nordiska medicinpriset 2015 for sin forskning innen idrettsmedisin og fysisk aktivitet - en pris de deler med professor Jón Karlsson, Göteborgs universitet, og professor Michael Kjær, Københavns universitet.

Lars Engebretsen er ortopedisk og idrettstraumatologisk konsulent ved Olympiatoppens helseavdeling. Han er også professor ved
Det medisinske fakultet ved Universitetet i Oslo og overlege ved Ortopedisk avdeling ved Oslo universitetssykehus. Dessuten er han medleder og professor II ved Senter for idrettsskadeforskning ved Norges idrettshøgskole. Engebretsen har doktorgrad i ortopedisk kirurgi. Fra 2007 har han vært ansvarlig for medisinsk forskning i IOC og medlem av IOCs medisinske komité.

Roald Bahr er sjeflege og leder for Olympiatoppens helseavdeling. Han er professor i idrettsmedisin og leder for Senter for idrettsskadeforskning ved Norges idrettshøgskole. Bahr har doktorgrad i idrettsmedisin. Sommeren 2008 ble han valgt inn som medlem av IOCs medisinske komité.

Nordiska medicinpriset er en av Nordens største medisinske priser og deles årlig ut til forskere som belønning for fremragende vitenskapelig prestasjon. Prissummen er på en million svenske kroner. Prisen er blitt utdelt siden 1998 av Ulf Nilsonnes Stiftelse i samarbeid med forsikringsselskapet Folksam. Og det er Nordens 16 medisinske fakulteter som nominerer kandidater til prisen.

\section{Gunn Marit Seberg}

Tidsskriftet 